\title{
Editorial
}

\section{Institutional Contexts of Education for Information}

\author{
Michael K. Buckland \\ School of Information, Berkeley, CA, USA \\ E-mail: buckland@berkeley.edu
}

Most education for information takes place through a programme administered by a school, commonly a department within a university. The institutional context of each school largely determines its possibilities and constraints. For that reason, examination of the institutional situations of schools is needed, but has so far been relatively neglected. The discourse of information professionals has much to say about professional education in relation to the perceived needs of professionals and of society, but it tends to overlook the reality that each school has to survive - and thrive if it can - in the economic, political and policy constraints and opportunities of the administrative context in which it is situated.

Schools in each country are influenced by the traditions, circumstances, and policies of that country and so schools within a single country have some features in common. But each individual school's situation is also and importantly a product of local conditions which reflect, for example, the institutional history and the evolving priorities of the parent institution and of funding agencies. For that reason a series of case-studies is needed to build a corpus of documented experience. To meet this need Education for Information has decided to feature a series of articles on schools and their institutional contexts.

The idea is to invite and encourage reflective accounts of experience with schools in a variety of different circumstances. Authors are encouraged to describe their institutional context, to describe significant developments (for good or for bad), to reflect on the tactics, strategies, and circumstances that were favorable or unfavorable, to speculate of what might have been done differently, and to suggest what could be learned that might be of wider interest.

Failures and disappointments are as instructive as successes. Innovations that are successful in one institutional context may be unwise or not feasible in another. Some thirty years ago when a few schools were discontinued in the United States, there were lessons to be learned, but discourse about them was mostly simplistic, erroneous, and overly generalized. In fact each case was uniquely different and the influential factors were quite varied. One lesson was clear, however, catering to professional constituencies is important but not enough. Neglecting local institutional imperatives is perilous. 
Our series starts with an account of the original and powerful interpretation of Library and Information Science introduced in 1996 at the University of Troms $\varnothing$ in northern Norway under the leadership of Niels W. Lund. The program was initially called Institute for Documentation Studies. It is now called Media and Documentation Studies and is a program within the Department of Language and Culture. Roswitha Skare, for many years an instructor in this program, has contributed a paper printed in this issue. It is planned to make such papers a recurring feature in future issues documenting a significant variety of experiences. 